ORIGINAL ARTICLE

\title{
Psychological support for people with dementia: A preliminary study
}

\author{
Kelly Birtwell $^{1, *}$ (D) \& Linda Dubrow-Marshall ${ }^{2}$ \\ 1 University of Manchester, Manchester,UK \\ 2 University of Salford, Salford, UK \\ *Corresponding author: Email: kelly.birtwell@outlook.com
}

Keywords: coping, dementia, loss, qualitative, support

doi: 10.1002/capr.12154

\begin{abstract}
Aim/Purpose: Evidence suggests nonpharmacological therapies could improve quality of life in people with Alzheimer's disease (Olazaran et al., 2010). This study aimed to explore attitudes to, and acceptability of, psychological support for people with mild dementia, from their perspective. Design/Methodology: Semi-structured interviews were conducted with five people identified from secondary care services. Questions concerned the experience of being diagnosed, experience of support services and their opinion of alternative support options. Interviews were audio-recorded, transcribed and analysed using thematic analysis. Results/ Findings: Three main themes were identified: loss, coping mechanisms and support. Loss of physical abilities was associated with loss of identity and place in the community. Coping mechanisms included asserting control, and growth and development, including engaging in new activities or using humour. Individual needs and preferences were key to effective support. Social aspects of support and opportunities to talk about their feelings were valued by participants. Counselling, mindfulness and group-based activities, including walking and gardening, were viewed positively. Support from admiral nurses or specialist nurses tended to be viewed in terms of physical health needs, and most needed in later stages of dementia. Research Limitations: Limitations include the small sample size, potential inaccuracies acknowledged by participants regarding recollections of events and researcher bias in hoping that psychological support would be well received. Conclusions/Implications: Talking therapies and psychosocial interventions are acceptable sources of support. Person-centred support which considers personal preferences and abilities can support people to live well with dementia.
\end{abstract}

\section{Introduction}

Approximately 850000 people in the United Kingdom are living with dementia (Alzheimer's Society, 2014), and this figure is expected to double in the next 30 years (Department of Health, 2009). Dementia is a neurodegenerative syndrome caused by a number of diseases, which share similar characteristics, such as Alzheimer's disease, dementia with Lewy bodies and vascular dementia. People with dementia may experience memory loss, mood changes, loss of motivation, depression and communication problems (NICE, 2006). As dementia progresses, activities of daily living become more difficult and there is a greater need for informal care from family and friends, formal (paid) care and medical care.

A diagnosis of dementia can significantly affect selfesteem and sense of 'personhood' (Husband, 1999), 
defined by Kitwood (1997) as 'a standing or status that is bestowed on one human being, by others, in the context of relationship and social being. It implies recognition, respect and trust...' (p. 8). Indeed Preston, Marshall and Bucks (2007) highlighted the importance of social aspects of coping with dementia, and the significance of psychosocial factors in influencing well-being and cognitive function in people with dementia has been noted (Harris, 2002; Sabat, 2001; Snyder, 2009). Sabat and colleagues have explored social relatedness and the effect of 'healthy others' on the sense of self and identity in people with dementia. Findings of qualitative research and case studies suggest that a focus on losses in functioning, or malignant positioning of the person with dementia by healthy others, can lead to a diminished or limited sense of self which may be restricted to an identity of patient or dysfunctional patient (Sabat, 2001, 2003; Sabat, Johnson, Swarbrick $\delta$ Keady, 2011). Conversely, the absence of malignant positioning, and a focus on abilities retained, can lead to the construction of a more valued social identity and sense of self (Sabat, 2002; Sabat \& Lee, 2012; Sabat, Napolitano \& Fath, 2004). According to Scholl and Sabat (2008), people with dementia are vulnerable to negative stereotyping from self and others, as well as stereotype threat, the mere threat of being stereotyped negatively. Both negative stereotyping and stereotype threat may exacerbate problems with cognitive functioning, increase anxiety and reduce quality of life (Scholl $\delta$ Sabat, 2008). In a recent study of illness representations in dementia, Clare, Quinn, Jones and Woods (2016) found an association between the representation of dementia as an 'illness' and low mood. How dementia is perceived by others and the person living with dementia is therefore important. Hulko (2009) suggested that not everyone with dementia views the condition as problematic and that conceptualisation of dementia relates to the social location of the individual.

Stigma and a lack of understanding can have a negative effect on quality of life. Following a diagnosis of dementia people often report losing friends and feeling lonely (Alzheimer's Society, 2013, 2014; Harman \& Clare, 2006). In a recent Alzheimer's Society survey, more than half of those participating said they had felt anxious or depressed recently (Alzheimer's Society, 2015). People may become more distressed or frustrated particularly in the early stages of Alzheimer's disease when they have more insight and awareness of their cognitive decline (Brierley et al., 2006). Therefore, support to understand and make sense of the diagnosis, as well as making positive adjustments, is important (Lee, Roen $\&$ Thornton, 2014).

\section{Psychological support}

In a systematic review of nonpharmacological therapies for people with Alzheimer's disease, Olazaran et al. (2010) concluded that nonpharmacological therapies have been found to be useful and potentially cost-effective interventions for improving quality of life for both people with dementia and their carers. However, a review by Robinson et al. (2009) stated it is not clear whether individual or group therapy is more effective, and it has been noted that medication is often prescribed for behavioural and psychological symptoms owing to a lack of availability of specialist psychological services (Robinson et al., 2009).

Clare et al. (2013) found a relationship between self-concept and quality of life and suggested that approaches to support self-concept could benefit people with dementia. Person-centred counselling is one way of supporting the self-concept and increasing self-acceptance. Indeed, Scholl and Sabat (2008) recommended approaches that incorporate elements of counselling to support people with dementia who are at risk of negative self-stereotyping or stereotype threat. They suggested quality of life and self-worth could be enhanced by focussing on attributes retained. Furthermore, the Prime Minister's Challenge on Dementia 2020 (Department of Health, 2015) has stressed the importance of support to improve quality of life after a diagnosis, while the Department of Health (2013) and Alzheimer's Society (2015) have stated more research is needed in this area.

\section{Rationale}

There is a lack of research exploring the views of people with dementia in relation to psychological support. Understanding attitudes to and acceptability of different types of psychological support, such as counselling and psychotherapy, from the perspective of people with dementia can help to inform the development and provision of services.

The rationale for this project is in line with the quality statements for supporting people to live well with dementia (NICE, 2013), which assert that people with dementia should have choice and control in decisions relating to their care and support, and that they should be enabled to access services that support 
their physical and mental health and well-being. It is important that people with dementia are given a voice to ensure the psychological services they may need access to are appropriate, accessible and meet their needs.

\section{Aim}

The aim of this study was to explore attitudes to, and acceptability of, psychological support for people with mild dementia, from their perspective, through qualitative interviews. The term psychological support included counselling, psychotherapy, other one-to-one psychological interventions [such as cognitive behavioural therapy (CBT)], group interventions (including mindfulness) and support from other sources such as admiral nurses.

\section{Methodology}

\section{Design}

This was a qualitative study using inductive thematic analysis (Braun \& Clarke, 2006), allowing for complex analysis without dependence on theory, which was the most suitable approach for this preliminary study. People with dementia were involved throughout the life of the study, thereby utilising the patient and public involvement in research process of co-creation. Patient advisors gave feedback on the study design and reviewed the interview schedule, participant information sheet and consent form to check whether the information and questions were appropriate and understandable. Changes were made according to their feedback; some language was altered and additional services included in the interview schedule. Individual interviews were chosen for the methodology rather than focus groups because as a preliminary study, the researchers were keen to gather as much individual information as possible without participants being influenced by what other people might say.

\section{Participants}

Participants were recruited from the Memory Assessment Services and the Young Onset Dementia Service of an NHS Mental Health Trust. Clinical teams identified potential participants and discussed the study with them. If potential participants agreed, their contact details were passed to the researcher so they could find out more about the study. The clinical teams ensured that any potential participants had the capacity to consent to a research study as well as sufficient speech and language skills to participate in an interview. Following discussions with the researcher, five people agreed to take part in the study (four female, one male; age 58-79). Three participants were white British and two were African Caribbean. All participants had received a diagnosis of dementia (Alzheimer's disease or vascular dementia). The length of time since diagnosis varied, ranging from 2 to 21 months. Although the researchers would have preferred a larger sample, the recruitment target was 4-6 participants based on the timelines of the project and funding available.

\section{Data collection}

Participants were interviewed by the first author. Four participants were interviewed in their own homes, and one participant was interviewed in a private room at the Young Onset Dementia Service, location being determined by participants. Participants were advised their caregiver or relative could attend the interview as an observer if they wished, and they could pause the interview at any time if they wanted to take a break or check anything with their carer/relative. Two participants were interviewed with a relative present. The researcher had discussed the project with all participants previously by telephone and discussed the study with them again prior to commencing the interviews. The researcher spent at least 30 minutes with each participant to build rapport, discuss the study and provide time for patients to further consider the study and to give consent (BACP, 2016).

A researcher capacity checklist was used (Dobson, 2008), and the researcher ensured all participants fully understood the study and demonstrated their capacity to consent, in line with approval from the Manchester East Research Ethics Committee (ref: 15/ NW/0327). The research interview was audiorecorded, and all participants were asked brief demographic questions and a series of open-ended questions, including questions about the emotional impact of living with dementia and the types of psychological support needed or received. Several types of support service were described by the interviewer (e.g. specialist and admiral Nurses, counselling, CBT, mindfulness, cognitive stimulation therapy (CST), support groups and peer support), and participants were asked for their opinion of the different types of service. These services were chosen because they were delivered either locally or nationally. 
Participants were also asked whether they had accessed any other services not listed in the interview schedule. Further examples were given or questions re-phrased if participants seemed not to understand their meaning. Formal audio-recorded interviews ranged in duration from 23 to 62 minutes. Following interviews, the researcher spent some time with each participant (typically at least 20 minutes) to ensure they felt comfortable and that they were not experiencing any distress due to the topic. Each participant was provided with a list of locally available support services and encouraged to access these or speak to their GP if they might need support. Interviews were transcribed by the first author and recordings and transcripts reviewed and checked for accuracy by the second author. Basic transcription of the spoken words was thought sufficient for the purposes of an exploratory study rather than a more detailed transcription used in conversation and discourse analysis, such as the 'Jefferson' system (1996).

\section{Data analysis}

Thematic analysis of the interviews was conducted within a realist framework, with the assumption that there is an external reality which can be observed and studied empirically (Giles, 2014; Green \& Thorogood, 2014), and which further incorporated an essentialist framework in the sense of acknowledging the 'fixed qualities 'inside' people (essences) that are impervious to the social context' (Braun \& Clarke, 2014, p. 330).

Interview transcripts were analysed in accordance with the five phases of thematic analysis described by Braun and Clarke (2006); after listening to interviews and reviewing transcripts, the authors independently coded features of the data and collated codes and initial themes. Themes were discussed, reviewed and revised by the authors at the level of individual coded extracts and the full data set. The main themes and subthemes were then refined and named by the authors collaboratively.

\section{Reflective statement}

Both authors take an integrative or pluralistic approach to their therapeutic work with clients, but are primarily from a person-centred background. It is possible that there is some bias towards relational forms of support and therapy, such as person-centred counselling and mindfulness-based interventions.

\section{Ethical issues}

Following approval by the Greater Manchester East Research Ethics Committee, and the Research and Innovation department of the participating NHS Trust, clinical teams confirmed that all potential participants had capacity to consent to the research, while a researcher capacity checklist was also used. A participant information sheet explained all aspects of the study and participants had the opportunity to discuss this with family and friends. On the day of the interviews, the researcher ensured participants understood and had given written informed consent before participating. Interviews were anonymised during transcription and pseudonyms used to protect the confidentiality of participants, in line with the study protocol. A lay summary of the research was prepared for participants using language that would be readily understood.

\section{Findings}

Three superordinate themes were identified from analysis of the data: loss, coping mechanisms and support (see Fig. 1). Each superordinate theme contained up to three subordinate themes, as described below.

\section{Loss}

All five participants spoke about feelings of loss, particularly the subordinate themes of loss of abilities and loss of identity. Loss of abilities included memory problems: 'it frustrates me when I can't remember and it's you know- I know I've only just said something about it and then I just can't remember and it's frustrating' (Barry). Some participants also experienced physical health problems such as difficulty walking, leading to a sense of loss about not being able to participate in group activities: 'I'm not walking at the moment. ....No, I've got bad knees' (Joan).

All participants spoke about problems carrying out their usual work or day-to-day tasks, and for Carol, the subsequent loss of her role as a teacher: 'I knew that I couldn't do things anymore. You know I had a computer and erm I looked at- I looked at a powerpoint and I just couldn't work it out at all. And I knew then that I couldn't continue' (Carol). One participant was concerned that he would not be able to complete diary sheets if offered CBT: 'I - I don't think I would be able to do that. No. Erm... it's how can I say ... one I don't write well' (Barry). 


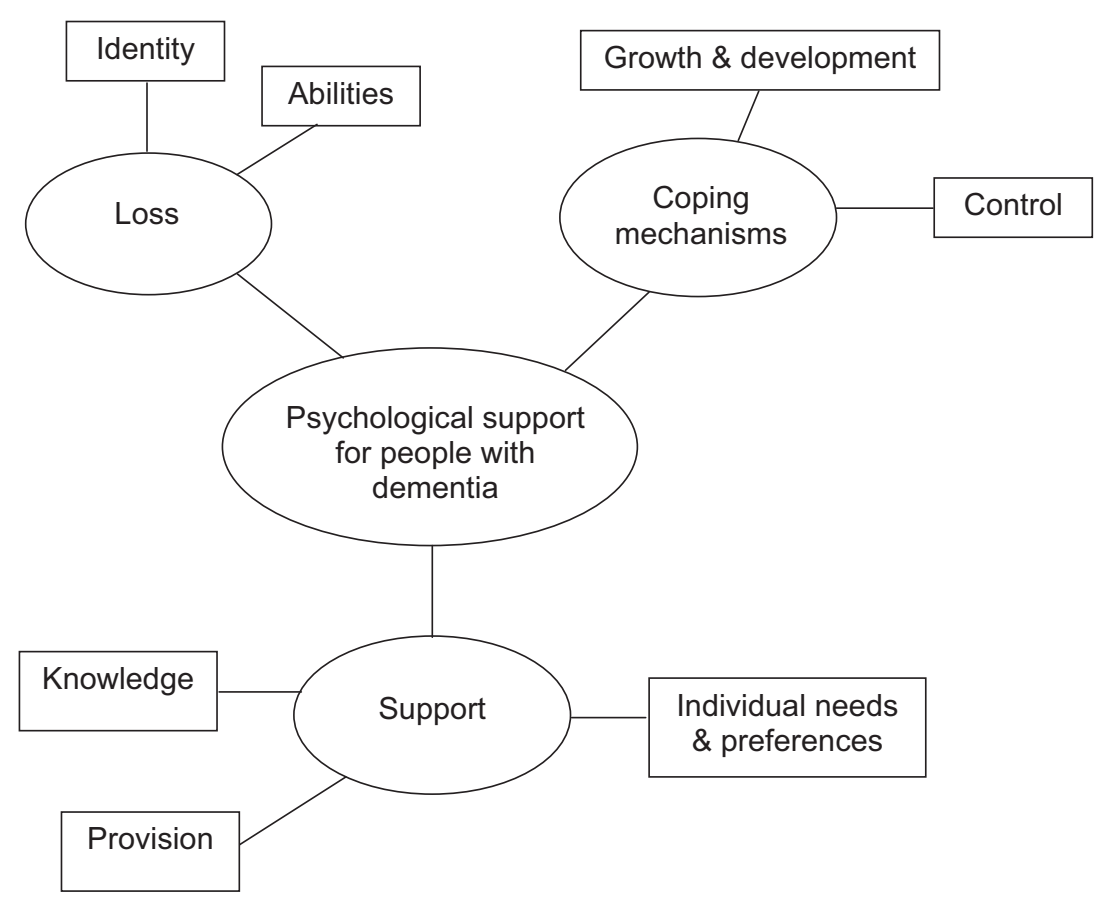

Fig. 1: Thematic map.

Loss of abilities was connected to loss of identity, through losing their working role or place in the community. Participants also reported losing friends, feeling lonely and experiencing the stigma associated with dementia: 'You be rejected by your friends. You be rejected by many people [cries]. The stigma of it. Those who you speak and listed [sic] before will not that be long.... maybe your true friend can reject you and is painful' (Clara). Although Clara used the word 'listed', this was interpreted as a grammatical error; English is her second language and she presumably meant 'listened'.

\section{Coping mechanisms}

Participants coped with their diagnosis in a range of ways and this theme was divided into the two subthemes of control, and growth and development. Carol discussed her fear of being diagnosed and losing control (being unable to 'do' anything about the dementia), as well as concerns about the impact on her family. Perhaps protectively, she initially experienced some denial: 'I suppose I put my head in the sand' (Carol), before moving towards acceptance and asserting control: 'I mean you have to get on with your life, don't you? And that's what I'll do' (Carol).

It was common for participants to assess their relative level of difficulty and compare this with others, or to compare changes within themselves, which gave some sense of control and reassurance in their ability to cope: 'some days are good and some days are bad' (Barry). 'I didn't feel really bad, you know. I didn't think I was sick that much anyway' (Joan). Beryl most clearly expressed this difficulty when she said: 'I don't want to be one of them people that goes out and starts wandering about, you know. Cos I've heard people do do that and that, that worries me a bit. But other than that, I'm not bad' (Beryl).

Growth and development, engaging in new activities and learning new skills, was associated with positive coping: 'coming out to do something it's like I'm going to work I look forward to it so I think it's a good thing. You learn new things to keep you going stimulate your brain' (Clara). Two participants talked about activities at a local gardening group, learning about seed drills and watering the plants: 'to me I'm giving them life' (Barry). The subtheme of growth and development included developing and maintaining social relationships: 'I think the main thing is to be occupied to be have somebody you can talk to, and company, I think that's the main thing' (Beryl).

Laughter was viewed as an important coping aspect of positive social relationships: 'get them to laugh. Really. Laugh and have a giggle and you know, that's... laughter's the best thing. ... If you don't laugh, you'll cry' (Barry). 


\section{Support}

The theme of 'support' included three subordinate themes: knowledge, provision and individual needs and preferences. Knowledge was seen as valuable about the condition, and about available support and services. Four participants spoke about a lack of support and not knowing where to go to access support: 'I would have liked more support erm for me as well as maybe my family and to have been erm pointed to services that you could get yeah' (Carol).

There were concerns around the provision of services, including accessibility: 'it's to get to where all the classes are, you know? It's probably difficult' (Joan), as well as financial cuts and eligibility for support: 'I'm very aware that it costs a lot of money' (Carol), and 'wouldn't it be taking er a place that somebody else might need?' (Barry).

A range of different options for support were discussed. Individual needs and preferences were key for engagement with support and services, including a person-centred approach from staff, and support for people at different stages of dementia: 'I think everyone has to do it in their own time' (Carol).

Opportunities to talk about feelings (through counselling or support groups) and social aspects of support were seen as valuable: 'coming here meeting with all the people has given me the hope' (Clara). 'you can talk, you know, let things out that you have inside you know, ... It was, very helpful' (Joan). Counselling and mindfulness were viewed particularly favourably: 'I would have had counselling if it had been on offer and I think it should be on offer for people who've got dementia. Erm... I would have thought it would be the first thing that you'd do' (Carol). Carol had already tried mindfulness and in fact mentioned this before being asked about it by the interviewer: 'I like mindfulness. Erm, I can sit on the floor and just you know be still'.

Group-based activities, including walking and gardening, were also viewed positively by all participants: 'you need to use your, your hands and your arms and your legs, you've got to. If you don't use em you lose em' (Beryl). Support from admiral nurses or specialist nurses tended to be viewed in terms of physical health needs and something that would be needed when the dementia had progressed further: 'I've not needed anything to do with nursing itself, but then I'm in the early stages I think, and I might need somebody after that' (Carol).

One participant highlighted a cultural issue, which demonstrates how people can have different experiences and different challenges: the African people to them they see shame. They term Alzheimer as a mental illness any dementia is like lunatics...you're of no use. A condemned person. ... So, that the persons who is suffering this, is suffering it the more because what nobody want to be associated with somebody that is mentally disturbed (Clara).

Clara wanted more education in her community to help people learn about the condition and increase available support.

\section{Discussion}

The aim of this study was to explore the attitudes to, and acceptability of psychological support for people with mild dementia, from the perspective of people with mild dementia. An inductive thematic analysis revealed three superordinate themes of loss, coping mechanisms and support. Identification of these themes provides additional confirmation of issues previously described in the literature.

The theme of loss reinforces previous qualitative research findings in which participants discussed feelings of loss (Harman \& Clare, 2006; Lee et al., 2014; Preston et al., 2007). In the present study, participants described a far-reaching range of losses, including in both physical and psychological domains, and extending beyond the readily identifiable loss of memory to other abilities. This in turn may necessitate adaptation to changes in self-identity, and loneliness resulting from losses of friendships and social standing.

A loss of identity was most clearly expressed by Carol who talked of the loss of her role as a teacher, and by Clara who discussed losing friends and the loss of her place in the community. Carol and Clara appear to have experienced 'role erosion' (Gillies \& Johnston, 2004) and malignant positioning by others (Sabat et al., 2004). However, Gillies and Johnston (2004) found that identity could be reclaimed, while Caddell and Clare (2012) suggested supporting identity could be beneficial for people with dementia experiencing problems with mood or quality of life. Psychologist Daniel Gottlieb (2008), who became a quadriplegic following a car accident, has eloquently described the need to incorporate a new identity and to ease suffering, by realistically changing the expectations that were previously held, so that achievements which would have been viewed as inconsequential can be celebrated and acknowledged as significant. This was reflected in the participants' experiences at the gardening group, as they learned 
new skills and found meaning and value in new roles such as 'giving life' to the plants. The cooperation of 'healthy others' in these activities supported individuals to construct what Sabat et al. (2004) referred to as a 'valued social identity'.

The second superordinate theme of coping mechanisms supported previous findings that coping mechanisms and strategies are important for adjusting to and living with dementia (Harman $\delta$ Clare, 2006; Lee et al., 2014; Preston et al., 2007). A subtheme in coping mechanisms was control, and it is possible that comparisons with themselves and others lent participants an illusory sense of control and helped to reduce a perceived sense of threat to self. Participants commonly compared themselves not only to how they used to be, but also to how other people with dementia were coping, which has been previously noted (Harman \& Clare, 2006; Preston et al., 2007; Sabat, 2001). This could be seen as an example of 'bargaining'; observed as part of the process of grief (Kubler-Ross, 1969; Penzo \& Harvey, 2008). In this case, the person consoles themself with the feeling that others have it worse, with an implied bargain that if I accept myself the way I am now, then perhaps I will never get as bad as that other person.

A similar dynamic was observed during group psychotherapy with patients with severe asthma, who sometimes took comfort in feeling that they were not the worst sufferer in the group (Dubrow-Marshall et al., 2014), individual and family therapy with hospitalised oncology patients (Dubrow-Marshall, 2002), and with patients with post-traumatic stress disorder who tended to minimise their suffering compared with the experiences of others, often without any logic to the comparisons (DubrowMarshall \& Dubrow-Marshall, 2009). Sabat (2001) wrote about the beneficial effects of taking control, if that is possible for the individual, and Scholl and Sabat (2008) suggested a strong internal locus of control can protect against stereotype threat as well as enhancing physical and mental health.

Within coping mechanisms, the second subtheme of growth and development was associated with positive coping, which would support viewing the person with dementia as a 'semiotic subject' capable of psychological agency (Sabat et al., 2011). This correlates with the philosophical framework for pluralistic counselling and psychotherapy (Cooper $\delta$ McLeod, 2011), 'which emphasises clients' perspectives, rights, strengths, and capacity to be agentic' (p. 80). Growth and development included learning new skills and developing and maintaining social relationships. This was an important aspect of positive coping as it supported the self-concept and sense of personhood, aiding the construction of a valued social identity (Sabat et al., 2004) and illustrating the impact of social relationships on positive coping (e.g. Kitwood, 1997; Preston et al., 2007).

The theme of support found in this study included subthemes of knowledge, provision and individual needs and preferences. Participants expressed a need for multiple layers of support, including accurate information about their condition and available resources, and the need to discuss feelings. While knowledge and the provision of support services were viewed as important, it was also acknowledged that the 'readiness' of the individual should be taken into account, including the suggestion that everyone should be able to access information and support in their own time. This finding supports previous research (Harman \& Clare, 2006; Preston et al., 2007) which highlighted the need for patient choice and consideration in accessing services.

The social aspects of support (also evident in other themes) appeared important in helping to reduce loneliness, fostering a sense of belonging and community, instilling hope and supporting identity. Within the theme of support the openness to counselling, mindfulness and group-based activities was most clearly revealed. When asked what they thought about CBT, there was a negative reaction from one participant who thought it would be too difficult. A cultural difference was poignantly described by one participant about feeling harshly judged within the African community, suggesting the need for a further area of study. This theme highlighted that personal and social factors are just as important as the biological factors in our understanding and treatment of people with illnesses (Sabat et al., 2011; Snyder, 2009). The types of support viewed more favourably by participants, were those which influenced self-concept and social identity. The findings therefore support the suggestion by Vernooij-Dassen and Moniz-Cook (2016) that person-centred care for people with dementia could move beyond traditionally held notions of caregiving, aiding them to fully embrace their capacities to live fully and joyfully.

\section{Limitations}

The study had a small sample size and therefore the findings may not be generalisable to the wider population of people with dementia. However, they provide an insight into some issues that affect people 
with dementia, supporting findings from previous research.

There were some challenges, particularly regarding the accuracy of participants' recollections, because of their dementia. This was particularly noticeable when participants were asked about the support that was offered to them following diagnosis, and their experiences during this time. However it was not considered significant enough to have adversely affected the content of the interviews. Two participants were interviewed with their caregiver present. None of the participants asked to stop the interview to discuss their responses with the caregiver, although one caregiver reminded a participant that an event they were talking about happened many years previously, before the onset of dementia.

The decision not to involve caregivers directly in the interviews was made because it was felt more important to hear the voice of the person with dementia directly, without potential external influences. It was also clear that some participants were more talkative than others. One participant provided succinct responses in the shortest recorded interview, but was more talkative before and after the interview when talking about their involvement in the study and other topics. It may have been helpful to have provided participants with more detailed information about interview topics in advance so they could take time to consider their experiences and their views.

\section{Implications for practice and future research}

This research study suggests the importance of person-centred support tailored to the needs of the individual based on preference and individual experience of dementia. This study also suggests that the abilities of the person with dementia should be taken into account. Adopting this approach will help guide counsellors to assess the likelihood of individuals engaging in or accessing a particular form of support. Participants' positive response to counselling and mindfulness may encourage counsellors to open their practice to a potentially very rewarding client group. Supervision could be used for consideration of issues relating to their own potential discomfort in working with people with dementia, to provide best practice, as with other client groups.

Qualitative researchers may find it valuable to spend some time with participants prior to conducting interviews, to build rapport and to become comfortable working with people with dementia.
Future research could explore the experiences of people with dementia in African Caribbean communities. This would also be in line with previous research which reported a lack of awareness of dementia in Black, Asian and minority ethnic communities in the UK and globally (Berwald, Roche, Adelman, Mukadam \& Livingston, 2016; Truswell, 2013). Studies could also look at group-based psychotherapy for people with dementia, building on the work of Cheston, Jones and Gilliard (2003). Incorporation of creative and expressive therapies into psychotherapy/counselling interventions can be considered, including blogging and creative writing (Swaffer, 2016), as can the advantages and disadvantages of involving carers/family members in such interventions.

\section{Conclusions}

People with mild dementia require person-centred psychological support, which takes account of their personal preferences, abilities and stage of readiness to access support. This study confirms the theme of loss amongst people with dementia, as found in previous research (Harman \& Clare, 2006; Lee et al., 2014; Preston et al., 2007). Additionally, the study indicates that psychosocial interventions including counselling and group-based interventions such as mindfulness, support groups, walking and gardening can be important sources of support for individuals with dementia to build a valuable, new social identity that embraces self-agency and efficacy. Insights were also revealed about participants' attitudes and preferences which may help those discussing support options with individuals with dementia, as well as those commissioning and providing services.

\section{Acknowledgement}

This work was supported by grant funding from the British Association for Counselling and Psychotherapy.

\section{References}

Alzheimer's Society (2013). Dementia 2013: The hidden voice of loneliness. London, UK: Author.

Alzheimer's Society (2014). Dementia 2014: Opportunity for change. London, UK: Author.

Alzheimer's Society (2015). Dementia 2015: Aiming higher to transform lives. London, UK: Author.

Berwald, S., Roche, M., Adelman, S., Mukadam, N., \& Livingston, G. (2016). Black African and Caribbean 
British communities' perceptions of memory problems: “We don't do dementia". PLOS ONE, 11, e0151878. https://doi.org/10.1371/journal.pone.0151878.

Braun, V., \& Clarke, V. (2006). Using thematic analysis in psychology. Qualitative Research in Psychology, 3(2), 77101. https://doi.org/10.1191/1478088706qp063oa

Braun, V., \& Clarke, V. (2014). Successful qualitative research. London, UK: Sage.

Brierley, E., Guthrie, E., Busby, C., Marino-Francis, F., Byrne, J., \& Burns, A. (2006). Psychodynamic interpersonal therapy for early Alzheimer's disease. British Journal of Psychotherapy, 19(4), 435-446. https://d oi.org/10.1111/j.1752-0118.2003.tb00097.x

British Association for Counselling and Psychotherapy (2016). Ethical framework for the counselling professions. Rutland, UK: Author.

Caddell, L. S., \& Clare, L. (2012). Identity, mood, and quality of life in people with early-stage dementia. International Psychogeriatrics, 24, 1306-1315. https://doi. org/10.1017/S104161021100278X

Cheston, R., Jones, K., \& Gilliard, J. (2003). Group psychotherapy and people with dementia. Aging and Mental Health, 7, 452-461. https://doi.org/10.1080/ 136078603100015947

Clare, L., Quinn, C., Jones, I. R., \& Woods, R. T. (2016). “I don't think of it as an illness": illness representations in mild to moderate dementia. Journal of Alzheimer's disease, 51, 139-150. https://doi.org/10.3233/JAD150794

Clare, L., Whittaker, C. J., Nelis, S. M., Martyr, A., Markova, I. S., Roth, I., ... Morris, R. G. (2013). Selfconcept in early stage dementia: profile, course, correlates, predictors and implications for quality of life. International Journal of Geriatric Psychiatry, 28(5), 494503. https://doi.org/10.1002/gps.3852

Cooper, M., \& McLeod, J. (2011). Pluralistic counselling and psychotherapy. London, UK: Sage.

Department of Health (2009). Living well with dementia: A national dementia strategy. Leeds, UK: Author.

Department of Health (2013). Dementia: A state of the nation report on dementia care and support in England. Retrieved from https://www.gov.uk/government/uploads/system/ uploads/attachment_data/file/262139/Dementia.pdf. Accessed on 19/09/2014.

Department of Health (2015). Prime Minister's challenge on dementia 2020. Retrieved from https://www.gov.uk/gove rnment/uploads/system/uploads/attachment_data/file/ 414344/pm-dementia2020.pdf. Accessed on 20/09/ 2015.

Dobson, C. (2008). Conducting research with people not having the capacity to consent to their participation: A practical guide for researchers. Leicester, UK: The British Psychological Society.

Dubrow-Marshall, L. (2002). Anxiety disorders among the elderly: when new fears arise and old ones return. Paper presented at the conference of the Anxiety Disorders Association of America, Austin, TX, USA.

Dubrow-Marshall, L., \& Dubrow-Marshall, R. (2009). Integrative treatment for survivors of abusive groups and relationships: Lessons from multiple contexts and multi-axial accounts. Paper presented at the Annual British Association for Counselling and Psychotherapy Research Conference: Portsmouth, UK.

Dubrow-Marshall, L., Yorke, J., Adair, P., Doyle, A., Niven, R., Fleming, S., ... Piltcher, C. (2014). A randomised controlled feasibility study of group-CBT (G-CBT) in severe asthma: A practitioner researcher's perspective. Paper presented at the Annual British Association for Counselling and Psychotherapy Research Conference, London, UK.

Giles, D. (2014). Advanced research methods in psychology. London, UK: Routledge.

Gillies, B., \& Johnston, G. (2004). Identity loss and maintenance: commonality of experience in cancer and dementia. European Journal of Cancer Care, 13:436-442. https://doi.org/10.1111/ecc.2004.13.issue-5

Gottlieb, D. (2008). Letters to Sam: A grandfather's lessons on love, loss, and the gifts of life. New York, NY, USA: Sterling.

Green, J., \& Thorogood, N. (2014). Qualitative methods for health research, 3rd edn. London, UK: Sage.

Harman, G., \& Clare, L. (2006). Illness representations and lived experience in early-stage dementia. Qualitative Health Research, 16(4), 484-502. https://doi.org/10. $1177 / 1049732306286851$.

Harris, P. B., Ed. (2002). The person with Alzheimer's disease: Pathways to understanding the experience. Baltimore, MD, USA: Johns Hopkins University Press.

Hulko, W. (2009). From 'not a big deal' to 'hellish': experiences of older people with dementia. Journal of Aging Studies, 23, 131-144. https://doi.org/10.1016/j.ja ging.2007.11.002

Husband, H. J. (1999). The psychological consequences of learning a diagnosis of dementia: three case examples. Aging and Mental Health, 3(2), 179-183. https://doi.org/ $10.1080 / 13607869956352$

Jefferson, G. (1996). A case of transcriptional stereotyping. Journal of Pragmatics, 26, 159-170. https://doi.org/10. 1016/0378-2166(96)00010-0

Kitwood, T. (1997). Dementia reconsidered: The person comes first. Maidenhead, UK: Open University Press.

Kubler-Ross, E. (1969). On death and dying. New York, NY, USA: Scribner.

Lee, S. M., Roen, K., \& Thornton, A. (2014). The psychological impact of a diagnosis of Alzheimer's disease. Dementia, 13(3), 289-305. https://doi.org/10. 1177/1471301213497080.

NICE (2006). Dementia: supporting people with dementia and their carers in health and social care. Retrieved from https://www.nice.org.uk/Guidance/CG42 
NICE (2013). Dementia:independence and wellbeing. Retrieved from https://www.nice.org.uk/guidance/ QS30

Olazaran, J., Reisberg, B., Clare, L., Cruz, I., PenaCasanova, J., del Ser, T., ... Muniz, R. (2010). Nonpharmacological therapies in Alzheimer's disease: a systematic review of efficacy. Dementia $\theta$ Geriatric Cognitive Disorders, 30:161-178. https://doi.org/10.1159/ 000316119

Penzo, J. A., \& Harvey, P. (2008). Understanding parental grief as a response to mental illness: implications for practice. Journal of Family Social Work, 11(3), 323-338. https://doi.org/10.1080/10522150802292616.

Preston, L., Marshall, A., \& Bucks, R. S. (2007). Investigating the ways that older people cope with dementia: a qualitative study. Aging $\theta$ Mental Health, 11 (2), 131-143. https://doi.org/10.1080/ 13607860600844572.

Robinson, L., Iliffe, S., Brayne, C., Goodman, C., Rait, G., Manthorpe, J., ... Care DeNDRoN Primary Group Clinical Studies. (2009). Primary care and dementia: 2. Long-term care at home: psychosocial interventions, information provision, carer support and case management. International Journal of Geriatric Psychiatry, 25(7):657-764. https://doi.org/10.1002/gps.v25:7

Sabat, S. R. (2001). The experience of Alzheimer's disease: Life through a tangled veil. Oxford, UK: Blackwell.

Sabat, R. (2002). Surviving manifestations of selfhood in Alzheimer's disease: a case study. Dementia: The International Journal of Social Research and Practice, $\mathbf{1}$ (1):25-36. https://doi.org/10.1177/ 147130120200100101

Sabat, S. R. (2003). Malignant positioning and the predicament of the person with Alzheimer's disease. In F. M. Moghaddam, \& R. Harré (Eds.), The Self and others: Positioning individuals and groups in personal, political, and cultural contexts, (pp. 85-98). Westport, CT, USA: Greenwood Publishing Group.

Sabat, S. R., Johnson, A., Swarbrick, C., \& Keady, J. (2011). The 'demented other' or simply 'a person'? Extending the philosophical discourse of Naue and Kroll through the situated self. Nursing Philosophy, 12, 282292. https://doi.org/10.1111/nup.2011.12.issue-4
Sabat, R., \& Lee, J. M. (2012). Relatedness among people diagnosed with dementia: social cognition and the possibility of friendship. Dementia: The International Journal of Social Research and Practice, 11(3):315-327. https://doi.org/10.1177/1471301211421069

Sabat, R., Napolitano, L., \& Fath, H. (2004). Barriers to the construction of a valued social identity: a case study of Alzheimer's disease. American Journal of Alzheimer's Disease and Other Dementias, 19, 177-185. https://doi. org/10.1177/153331750401900311

Scholl, J. M., \& Sabat, S. R. (2008). Stereotypes, stereotype threat and ageing: implications for the understanding and treatment of people with Alzheimer's disease. Ageing $\theta$ Society, 28:103-130. https://doi.org/10.1017/ S0144686X07006241

Snyder, L. (2009). Speaking our minds: What it's like to have Alzheimer's, Revised edn. Baltimore, MD, USA: Health Professions Press.

Swaffer, K. (2016). What the hell happened to my brain? Living beyond dementia. London, UK: Jessica Kingsley.

Truswell, D. (2013). Black, Asian and minority ethnic communities and dementia: Where are we now? Better Health Briefing 30. Race Equality Foundation.

Vernooij-Dassen, M., \& Moniz-Cook, E. (2016). Personcentred dementia care: moving beyond caregiving. Aging $\theta$ Mental Health, 20, 667-668https://doi.org/10. 1080/13607863.2016.1154017.

\section{Biographies}

Kelly Birtwell (MBACP) is a Doctoral Researcher at the University of Manchester, researching mindfulness-based interventions for people with long-term conditions. She is also a counsellor and a mindfulness teacher.

Dr. Linda Dubrow-Marshall, MBACP (Accred), is an HCPC-registered counselling and clinical psychologist and course leader for the programmes MSc Applied Psychology (Therapies) and MSc Psychology of Coercive Control at the University of Salford. 